\title{
Geriatric slim implants for complete denture wearers: clinical aspects and perspectives
}

This article was published in the following Dove Press journal:

Clinical, Cosmetic and Investigational Dentistry

28 August 2013

Number of times this article has been viewed

\author{
Cedric Huard ${ }^{2}$ \\ Marion Bessadet ${ }^{1,2}$ \\ Emmanuel Nicolas ${ }^{1,2}$ \\ Jean-Luc Veyrune ${ }^{1,2}$ \\ 'Clermont Université, Université \\ d'Auvergne, Centre de Recherche \\ en Odontologie Clinique, Clermont- \\ Ferrand, France; ${ }^{2} \mathrm{CHU}$ Clermont- \\ Ferrand, Service d'Odontologie, \\ Clermont-Ferrand, France
}

Background: Advances made in prevention have helped postpone complete edentulism in older patients. However, in the elderly, the physiological state reduces patients' ability to adapt to oral rehabilitation and degrades the patient's oral condition. Consequently, elderly edentulous subjects avoid many types of foods, which can lead to substantial nutritional consequences. Complete dentures retained by implants are, currently, the treatment of reference in prosthodontic mandibular rehabilitation. Indeed, the mandibular symphysis generally tolerates implantation, even when the mandible is strongly resorbed. However, in the elderly, implant rehabilitation is compromised by the complexity of the surgical protocol and possible postoperative complications. In this context, the use of geriatric "slim implants" (GSI) offers an interesting alternative.

Methods: In the present study, the surgical and prosthetic procedures for the use of GSI in a French dental hospital are presented. The objective was the stabilization of a complete mandibular denture in an elderly person, with the immediate implantation of four GSI.

Results: The operating procedure was found to be less invasive, less expensive, simpler, and more efficient than the conventional procedure.

Conclusion: The result strongly suggests that this protocol could be used systematically to treat complete edentulism in very elderly patients. Long-term monitoring and the evaluation of the reliability of this type of rehabilitation should be undertaken.

Keywords: gerodontology, oral health, prostheses, mini-implant

\section{Introduction}

Nowadays, the loss of the last remaining teeth is delayed, due to oral prevention; consequently, the prevalence of edentulousness increases with age. In Europe, the prevalence of edentulism of persons between 65 and 74 years old ranges from $12.8 \%$, in Italy, to $69.6 \%$, in Iceland. ${ }^{1,2}$ Thus, rehabilitation of edentulism occurs later in life, and the integration of complete dentures is increasingly difficult with age. ${ }^{3}$ Indeed, aging reduces adaptive capacity and degrades clinical oral status. ${ }^{4}$ In particular, bone resorption significantly reduces available bone volume. The buccal mucosa becomes thinner and weakens, creating an additional difficulty for prosthetic tolerance. ${ }^{5}$ Under these conditions, the design of a conventional functional, removable complete denture becomes difficult or impossible. As a result, the edentulous elderly avoid many types of foods, particularly raw vegetables, because chewing is difficult with conventional complete dentures. ${ }^{6-8}$ Dental status, among other factors, has an impact on the nutritional status of the elderly. ${ }^{9,10}$ It has been shown that subjects wearing conventional complete dentures have a lower nutritional intake than do subjects having more than 20 teeth. ${ }^{11}$ Worldwide, the prevalence of malnutrition is reported to be high in the
Correspondence: Emmanuel Nicolas University of Auvergne, Dental Faculty, II bd Charles de Gaulle, 630000 Clermont-Ferrand, France Tel +330473177382 Fax +330473177388

Email emmanuel.nicolas@udamail.fr 
elderly, varying between $2 \%$ and $10 \%$ for autonomous senior subjects. ${ }^{12}$ Multiple factors other than the dental status may have an impact on nutrition, among which is muscular force, which decreases as a function of age, leading to extended mastication time $e^{9,13}$ - therefore, the capacity to form a bolus that allows swallowing (plastic, cohesive, and slippery) is jeopardized. ${ }^{14}$

From a technical viewpoint, successful prosthetic integration depends on the stability and maintenance of the prosthesis. In the past, the only strategy for preventing problems involved the use of prosthetic adhesive or retention by attachments. ${ }^{15}$ When using an attachment system, residual tooth roots can stabilize a denture and allow conservation of the alveolar bone structure. In the absence of roots, a complete denture retained by two implants is considered as the minimal treatment for the rehabilitation of an edentulous mandible. ${ }^{16,17}$ Indeed, the symphyseal region generally allows implant treatments even when the mandibles are strongly resorbed. The dental implant may be compared with an artificial dental root onto which a prosthetic device can be screwed, sealed, or retained (single crown, bridge, or denture). Thus, with additional retention, these implants could provide comfort and provide a function similar to those of toothed subjects. ${ }^{18,19}$ However, for very old or vulnerable patients, a complex surgical procedure and its consequences could compromise standard implant rehabilitation. In addition, given their socioeconomic status, the high cost of implant use can be an additional barrier. In this context, the stabilization of complete mandibular denture by "geriatric slim implants" (GSI) could be an interesting treatment option.

GSI, often named "mini-implants", are characterized by a diameter of less than $3 \mathrm{~mm}$. These implants have proven useful for orthodontic or temporary treatment. ${ }^{20-22}$ GSI can be inserted via flapless surgical techniques, with no pain and edema, even in the presence of atrophic mandibles. ${ }^{23-27}$ Furthermore, the monolithic structure of GSI decreases the risk of contamination of the abutment-implant interface. ${ }^{28}$ Dental implants can be loaded immediately or after a delay. The immediate loading of GSI is a well-documented surgical prosthetic procedure ${ }^{29,30}$ that instantly restores aesthetics, comfort, and chewing, with significant nutritional consequences. ${ }^{31}$ Its success rate of over $95 \%$ is comparable to that of delayed loading. ${ }^{32}$

Indeed, immediate loading enables the transmission of the masticatory forces on the bone, and this endosseous stimulation, when moderate, may favor osteogenesis. The formation of new osseous blood capillaries at the surgical site is stimulated, and the density of the peri-implant bone is then improved compared with that observed in delayed loading. The elimination of the delay between implant setting and prosthetic restoration avoids the wearing of a transitional prosthesis, thereby improving the patient's comfort and providing better chewing and therefore, better treatment acceptability. ${ }^{31}$ Repeated studies have shown that these findings also apply to conventional implants used to retain overdentures. ${ }^{33,34}$ Successful immediate loading is facilitated by the use of a rigid suprastructure, which enables the bone integration of the implant by applying a force along the entire implant-prosthetic structure. ${ }^{35,36}$

However, none of the studies cited above address the use of GSI for the stabilization of a complete mandibular denture. For this type of rehabilitation, a simple procedure of immediate loading of four GSIs, using a flapless procedure, could be proposed. This is a case report of the use of a type of GSI (Obi Mini ball implant ø2.7; Euroteknika Group, Sallanches, France) in a procedure commonly used at the Dental Hospital of Clermont-Ferrand (France).

\section{Proposal for elderly patients: clinical rehabilitation by GSI General conditions of use}

This method of oral rehabilitation is recommended in presence of unstable complete mandibular denture. ${ }^{16,37,38}$ Patients with incompatible oral or general diseases should not be scheduled for this surgical procedure. GSI are not indicated for patients with unstable systemic disorders or rheumatoid polyarthritis treated with corticoid therapy. Regarding patients with stable systemic disorders, the use of GSI treatment is accepted after a case-by-case decision, based on the patient's general health status.

Three steps preceding implantation can be described: (1) radiopaque plots are inserted in the prosthesis, to the left and right of the canines; (2) the prosthesis is placed in the mouth, and an X-ray is taken to measure the space between the radiopaque plot of the prosthesis and the interforamen space (Figure 1); and (3) the interforamen space is marked accordingly with a mucosal pencil, indicating to the surgeons the situation of the foramens and delimiting the placement of the implants. In the described case, the implants used were $2.7 \mathrm{~mm}$ in diameter and from 9 to $15 \mathrm{~mm}$ in length. These implants were self-tapping, sandblasted, and etched. After drying the mucous membranes, the marks delimitating the emergence of the mental foramen were plotted on the crest, to delimit the area of parasymphyseal implant placement. Transmucosal drilling was performed with a single $2 \mathrm{~mm}$ diameter drill (Figure 2). The implants had to be placed as 


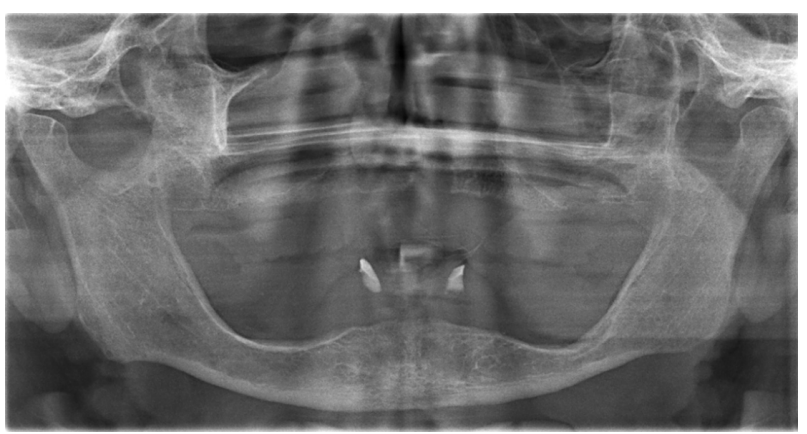

Figure I A preoperative panoramic radiograph was performed to mark the two most posterior implant placement sites with respect to the mandibular foramen.

parallel an arrangement to each other as possible (with a tolerance of $10^{\circ}$ ) and perpendicular to the occlusal plane (Figure 3). They were inserted using a ratchet and buried as deeply as possible. After surgery, the denture was recessed in the parasymphyseal area to avoid interference with the heads of the implants. Then, under occlusal pressure, the prosthesis was secured against the female parts of the O-ring prosthesis attachment using a self-polymerizable methacrylic resin (PaladurR, Heraeus Materials Technology GmbH \& Co. KG, Hanau, Germany) (Figure 4). Afterwards, the denture was secured by clipping onto the set implants (Figure 5). A panoramic, control radiograph was then taken (Figure 6).

\section{Clinical aspects}

The benefits of the GSI for the elderly and for frail persons are numerous, especially because of the specific characteristics of the surgical procedure. Indeed, the flapless technique reduces perioperative stress and surgery duration and therefore, postoperative complications, with no increased surgical risk. ${ }^{39}$ Traditional protocols for implant surgery with flap require direct access to the bone during drilling, and this approach requires subperiosteal elevation of a full-thickness flap.

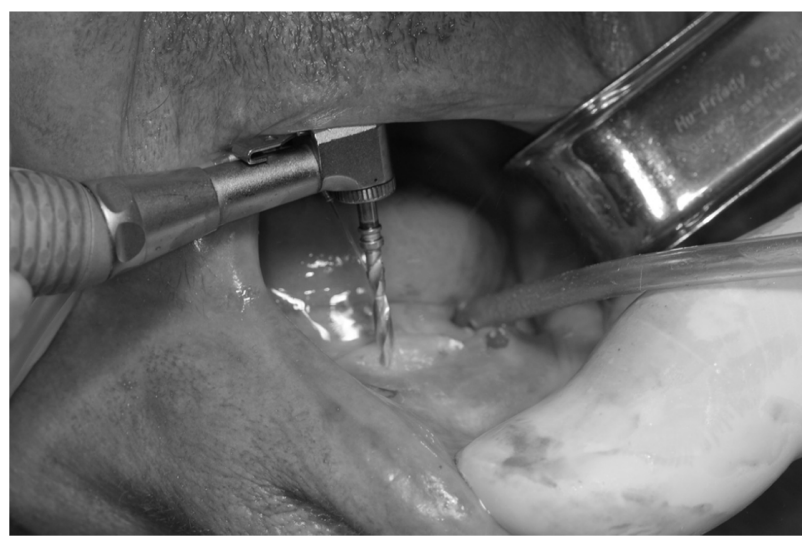

Figure 2 Intrabone drilling directly through the mucosa.

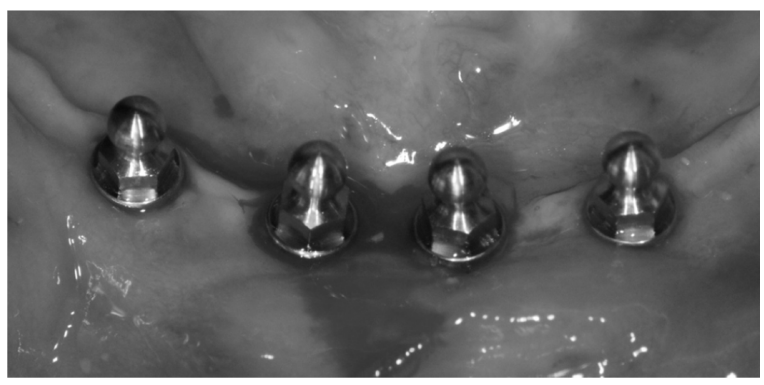

Figure 3 Insertion of implants.

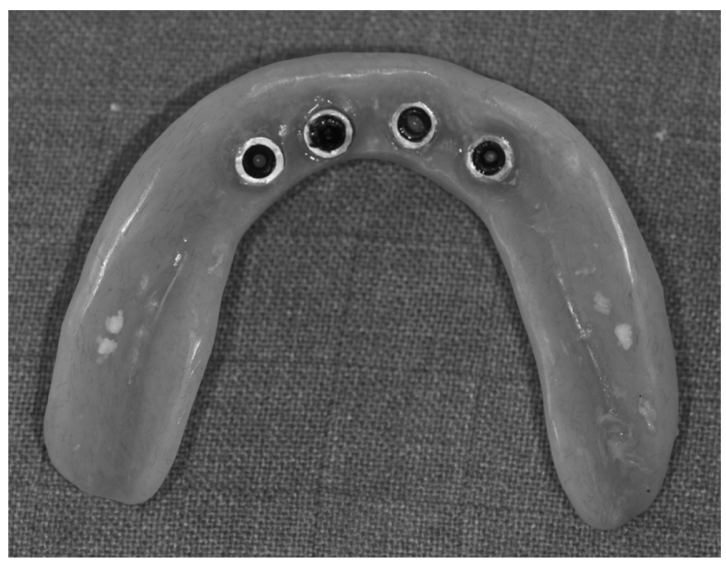

Figure 4 Connection of the female-portion attachments to the impression surface of the denture.

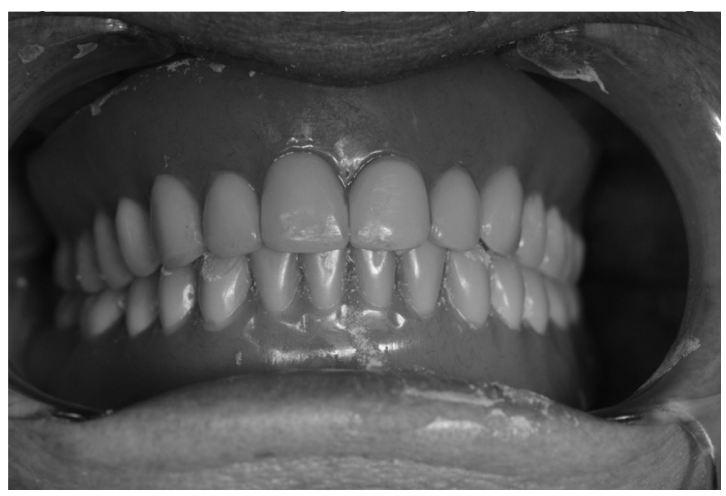

Figure 5 Immediate loading of the implant/denture complex.

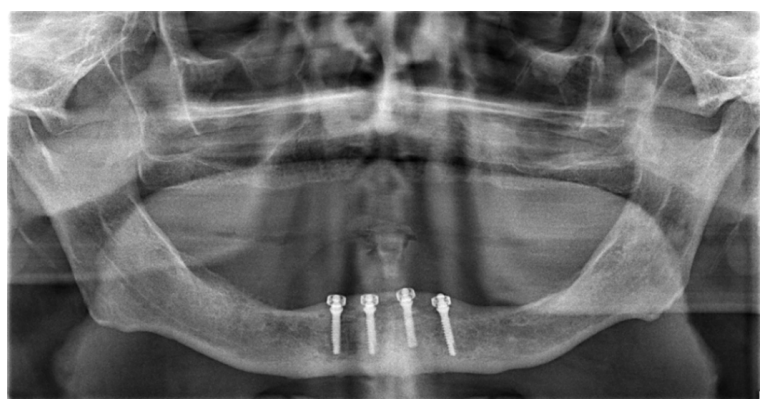

Figure 6 Radiographic control. 
The flap separation deprives the bone of periosteal vascular contributions. Therefore, resorption has been observed during the healing phase, due to the compromised bone vascularization alone. In addition, removing the flap from the bone makes the latter more prone to microbial exposure, and infectious complications can be expected despite the use of aseptic procedures. Furthermore, the survival rate of flapless implants is identical to that observed in implants with flaps, and using flapless implants constitutes an advantage for the elderly. ${ }^{40}$ The use of a single drill reinforces this benefit - indeed, heating of the bones related to drilling is a major factor in implant failure. For appropriate bone remodeling, the critical temperature of $47^{\circ} \mathrm{C}$ for 1 minute must not be exceeded..$^{41}$ The use of a single, small-diameter drill limits the drilling duration and thus, reduces the risk of overheating. Due to these features, GSI can be used in almost any clinical situation, even in the presence of a narrow ridge, where they can be implemented without prior adjustment of the ridge.

This prosthetic procedure is particularly suited for the elderly. Indeed, the stabilization of a denture by GSI can be compared with an immediate loading, which is very beneficial for the patient. Both function and comfort are improved from the first day onward. The success rate of this technique is probably closely linked to the implant-prosthesis connection mode and to the spatial distribution of the implants. An O-ring system ensures connection, comprising a male part (a metallic ball) and a female part (the O-ring inserted into a metallic ring). The rubber O-ring absorbs micromovements. The attachment of the prosthesis is performed under occlusal pressure to ensure that the denture impression surface is in full contact with the ridge. Consequently, during chewing, the elasticity of the O-ring will ensure that a significant fraction of the masticatory forces exerted will be directed to the mucosa and not to the implants - some implant complications are related to occlusal overload. Therefore, unloading the intraprosthetic cup can disperse the forces on the mucosa and ensure implant health. Thus the O-ring system is particularly suitable for immediate loading because of its shock absorption capacity. The distribution, number, and position of the implants are also contributing factors for osseointegration. Indeed, a minimum of three implants is necessary to optimize biomechanical behavior. Raising the number of implants to four increases the bone-implant surface interface. Thus the forces transferred to the bone for the same surface area are decreased, and osseointegration is encouraged. In addition, the four implants form a trapezoid, with the angles varying according to the mandibular anatomy of the patient. In comparison with a two-implant configuration, better prosthesis stability is achieved, due to the decrease in axis rotation. During implantation, it is better to position the side implants at the most posterior site possible (within the limit of the mental foramen) to increase the distance between the implants and decrease distal extension. The lever arm of the extension is decreased, and consequently, the nonvertical forces on the implants are reduced, leading to better denture balance.

Regarding the financial aspect, GSI are less expensive than conventional implants, regardless of the manufacturer, and may be offered for a reasonable cost. This is particularly important when we address the elderly, whose income is often modest.

GSI rehabilitation should improve masticatory function. Thus, significant nutritional consequences are expected. Indeed, it has been shown that the chewing parameters of mastication were improved in patients whose prosthesis was stabilized with implants; when measured, the kinematic parameters and particle sizes were similar to those reported in normally toothed patients. ${ }^{42}$ The elderly may vary and thus increase the range of foods habitually consumed. Additional studies are required to confirm this benefit, as several studies did not report a link between malnutrition and chewing function. ${ }^{43,44}$

In many cases, the use of GSI is advantageous; however, a number of shortcomings can be listed. Although the implant insertion appears easy, the use of a single drill implies that all implant axes must be correct from the outset, without any error in the estimation of parallelism. Indeed, no second drill with larger diameter can be used to correct any axis error. The flapless procedure requires a practitioner with solid experience in conventional implant setting. ${ }^{45}$ In addition, to maintain sustainability of the implant, a width of $2 \mathrm{~mm}$ of keratinized gingiva is necessary. ${ }^{46}$ In geriatrics, this could particularly restrict the use of the flapless mini-implant. Since the GSI is a one-piece implant (with the abutment integrated in the implant), the male section of the attachment cannot be changed in the case of wear. Retention could then be improved by increasing the hardness of the O-ring rubber, but only to a certain extent. Therefore, this technique should not be recommended in patients less than 70 years old. The practitioner performing the denture installation must rely on clinical experience in the use of this technique. Therefore it may be necessary to use another implant-prosthesis connection mode that is easier to manage in terms of retention force and monitoring, such as the Locator ${ }^{\circledR}$ Root Attachment System (Zest Anchors, Escondido,CA, USA). Furthermore, as with any other type of implant, independent acute complications could appear, in particular, cases of primary implant 
Table I Advantages and disadvantages of the GSI

\begin{tabular}{lll}
\hline & Advantage & Disadvantage \\
\hline $\begin{array}{l}\text { Surgical } \\
\text { procedure }\end{array}$ & $\begin{array}{l}\text { Transmucosal, single drill; } \\
\text { few postoperative reactions }\end{array}$ & $\begin{array}{l}\text { Solid experience in } \\
\text { conventional implant- } \\
\text { setting needed }\end{array}$ \\
$\begin{array}{lll}\text { Prosthetic } \\
\text { aspect }\end{array}$ & $\begin{array}{l}\text { Immediate loading; no removable } \\
\text { abutment; one implant loss does } \\
\text { not compromise prosthesis }\end{array}$ & $\begin{array}{l}\text { Abutment cannot be } \\
\text { changed, implant- } \\
\text { prostheses connection }\end{array}$ \\
retention & not easy to perform \\
aspect & Less expensive than conventional & GSI is not \\
& implant procedure and adequate & recommended in very \\
for the elderly & young patients
\end{tabular}

Abbreviation: GSI, geriatric slim implant.

loss or severe inflammatory reaction. Some chronic disorders, such as peri-implantitis, can be observed but rarely due to the characteristic of the "one-part" implant, which decrease this specific risk. A synthesis of the advantages and disadvantages of the GSI procedure is proposed in Table 1.

\section{Conclusion}

In conclusion, GSI constitute an additional therapeutic treatment against edentulousness. The protocol presented here allows the oral rehabilitation of vulnerable subjects, whose general health excludes overly invasive surgery. In addition, the cost of conventional implant treatment is often out of reach for elderly patients who have been edentulous for long periods. Thus, although the McGill consensus ${ }^{16,38}$ on the "two implants" setting remains the reference in terms of mandibular complete rehabilitation, the protocol developed with four GSIs could be an interesting alternative for the care of very old and completely edentulous patients. However, the reliability of this procedure needs to be validated in a follow-up study. In parallel, assessment of the impact of such rehabilitation on masticatory and dietary behaviors and of its nutritional consequences would be of great interest

\section{Disclosure}

The authors report no conflicts of interest in this work.

\section{References}

1. Bourgeois D, Nihtila A, Mersel A. Prevalence of caries and edentulousness among 65-74-year-olds in Europe. Bull World Health Organ. 1998;76(4):413-417.

2. Crocombe LA, Mejia GC, Koster CR, Slade GD. Comparison of adult oral health in Australia, the USA, Germany and the UK. Aust Dent J. 2009;54(2):147-153.

3. Burt BA. Epidemiology of dental diseases in the elderly. Clin Geriatr Med. 1992;8(3):447-459.

4. Masoro EJ. Physiology of aging. Int J Sport Nutr Exerc Metab. 2001;11:Suppl:S218-222.

5. Pelosse JJ, Pernier C. Physiology specific to adults. Orthod Fr. 2011;82(1):5-22. French.
6. Wayler AH, Chauncey HH. Impact of complete dentures and impaired natural dentition on masticatory performance and food choice in healthy aging men. J Prosthet Dent. 1983;49(3):427-433.

7. Tsakos G, Herrick K, Sheiham A, Watt RG. Edentulism and fruit and vegetable intake in low-income adults. J Dent Res. 2010;89(5): 462-467.

8. Cousson PY, Bessadet M, Nicolas E, Veyrune JL, Lesourd B, Lassauzay C. Nutritional status, dietary intake and oral quality of life in elderly complete denture wearers. Gerodontology. 2012;29(2): e685-e692.

9. Budtz-Jørgensen E, Chung JP, Rapin CH. Nutrition and oral health. Best Pract Res Clin Gastroenterol. 2001;15(6):885-896.

10. Palmer CA. Gerodontic nutrition and dietary counseling for prosthodontic patients. Dent Clin North Am. 2003;47(2):355-371.

11. Sheiham A, Steele JG, Marcenes W, et al. The relationship among dental status, nutrient intake, and nutritional status in older people. J Dent Res. 2001;80(2):408-413.

12. Guigoz Y. The Mini Nutritional Assessment (MNA) review of the literature - What does it tell us? J Nutr Health Aging. 2006;10(6): 466-485; discussion 485-487.

13. Mishellany-Dutour A, Renaud J, Peyron MA, Rimek F, Woda A. Is the goal of mastication reached in young dentates, aged dentates and aged denture wearers? Br J Nutr. 2008;99(1):121-128.

14. Prinz JF, Lucas PW. An optimization model for mastication and swallowing in mammals. Proc Biol Sci. 1997;264(1389):1715-1721.

15. Nicolas E, Veyrune JL, Lassauzay C. A six-month assessment of oral health-related quality of life of complete denture wearers using denture adhesive: a pilot study. J Prosthodont. 2010;19(6):443-448.

16. Feine JS, Carlsson GE, Awad MA, et al. The McGill consensus statement on overdentures. Montreal, Quebec, Canada. May 24-25, 2002. Int J Prosthodont. 2002;15(4):413-414.

17. Melescanu Imre M, Marin M, Preoteasa E, Tancu AM, Preoteasa CT. Two implant overdenture - the first alternative treatment for patients with complete edentulous mandible. J Med Life. 2011;4(2):207-209.

18. Feine JS, Lund JP. Measuring chewing ability in randomized controlled trials with edentulous populations wearing implant prostheses. J Oral Rehabil. 2006;33(4):301-308.

19. Emami E, Heydecke G, Rompré PH, de Grandmont P, Feine JS. Impact of implant support for mandibular dentures on satisfaction, oral and general health-related quality of life: a meta-analysis of randomizedcontrolled trials. Clin Oral Implants Res. 2009;20(6):533-544.

20. Froum SJ, Simon H, Cho SC, Elian N, Rohrer MD, Tarnow DP. Histologic evaluation of bone-implant contact of immediately loaded transitional implants after 6 to 27 months. Int J Oral Maxillofac Implants. 2005;20(1):54-60.

21. Shatkin TE, Shatkin S, Oppenheimer BD, Oppenheimer AJ. Mini dental implants for long-term fixed and removable prosthetics: a retrospective analysis of 2514 implants placed over a five-year period. Compend Contin Educ Dent. 2007;28(2):92-99; quiz 100.

22. Sohrabi K, Mushantat A, Esfandiari S, Feine J. How successful are small-diameter implants? A literature review. Clin Oral Implants Res. 2012;23(5):515-525.

23. Campelo LD, Camara JR. Flapless implant surgery: a 10-year clinical retrospective analysis. Int J Oral Maxillofac Implants. 2002;17(2): 271-276.

24. Sclar AG. Guidelines for flapless surgery. J Oral Maxillofac Surg. 2007;65(7 Suppl 1):20-32.

25. Brodala N. Flapless surgery and its effect on dental implant outcomes. Int J Oral Maxillofac Implants. 2009;24 Suppl:118-125.

26. Lerner H. Minimal invasive implantology with small diameter implants. Implant Practice. 2009;2(1):30-35.

27. Cawood JI, Howell RA. A classification of the edentulous jaws. Int J Oral Maxillofac Surg. 1988;17(4):232-236.

28. Rack A, Rack T, Stiller M, Riesemeier H, Zabler S, Nelson K. In vitro synchrotron-based radiography of micro-gap formation at the implantabutment interface of two-piece dental implants. J Synchrotron Radiat. 2010;17(2):289-294. 
29. Chiapasco M, Gatti C. Implant-retained mandibular overdentures with immediate loading: a 3- to 8-year prospective study on 328 implants. Clin Implant Dent Relat Res. 2003;5(1):29-38.

30. Attard NJ, Zarb GA. Immediate and early implant loading protocols: a literature review of clinical studies. J Prosthet Dent. 2005;94(3): 242-258.

31. Misch CE, Hahn J, Judy KW, et al; Immediate Function Consensus Conference. Workshop guidelines on immediate loading in implant dentistry. November 7, 2003. J Oral Implantol. 2004;30(5):283-288.

32. Esposito M, Grusovin MG, Willings M, Coulthard P, Worthington HV. The effectiveness of immediate, early, and conventional loading of dental implants: a Cochrane systematic review of randomized controlled clinical trials. Int J Oral Maxillofac Implants. 2007;22(6):893-904.

33. Cannizzaro G, Leone M, Esposito M. Immediate functional loading of implants placed with flapless surgery in the edentulous maxilla: 1-year follow-up of a single cohort study. Int J Oral Maxillofac Implants. 2007;22(1):87-95.

34. Roe P, Kan JY, Rungcharassaeng K, et al. Immediate loading of unsplinted implants in the anterior mandible for overdentures: a case series. Int J Oral Maxillofac Implants. 2010;25(5):1028-1035.

35. Gatti C, Haefliger W, Chiapasco M. Implant-retained mandibular overdentures with immediate loading: a prospective study of ITI implants. Int J Oral Maxillofac Implants. 2000;15(3):383-388.

36. Ahn MR, An KM, Choi JH, Sohn DS. Immediate loading with mini dental implants in the fully edentulous mandible. Implant Dent. 2004;13(4):367-372.

37. Feine JS, Carlsson GE, Awad MA, et al. The McGill consensus statement on overdentures. Mandibular two-implant overdentures as first choice standard of care for edentulous patients. Gerodontology. 2002;19(1):3-4.
38. Feine JS, Carlsson GE, Awad MA, et al. The McGill consensus statement on overdentures. Mandibular two-implant overdentures as first choice standard of care for edentulous patients. Montreal, Quebec, May 24-25, 2002. Int J Oral Maxillofac Implants. 2002;17(4):601-602.

39. Al-Juboori MJ, bin Abdulrahaman S, Subramaniam R, Tawfiq OF. Less morbidity with flapless implant. Dent Implantol Update. 2012; 23(4):25-30.

40. Maló P, Nobre M. Flap vs flapless surgical techniques at immediate implant function in predominantly soft bone for rehabilitation of partial edentulism: a prospective cohort study with follow-up of 1 year. Eur J Oral Implantol. 2008;1(4):293-304.

41. Eriksson AR, Albrektsson T. Temperature threshold levels for heatinduced bone tissue injury: a vital-microscopic study in the rabbit. J Prosthet Dent. 1983;50(1):101-107.

42. Veyrune JL, Opé S, Nicolas E, Woda A, Hennequin M. Changes in mastication after an immediate loading implantation with complete fixed rehabilitation. Clin Oral Investig. 2013;17(4):1127-1134.

43. Wöstmann B, Michel K, Brinkert B, Melchheier-Weskott A, Rehmann P, Balkenhol M. Influence of denture improvement on the nutritional status and quality of life of geriatric patients. J Dent. 2008;36(10):816-821.

44. Altenhoevel A, Norman K, Smoliner C, Peroz I. The impact of self-perceived masticatory function on nutrition and gastrointestinal complaints in the elderly. J Nutr Health Aging. 2012;16(2):175-178.

45. Sunitha RV, Sapthagiri E. Flapless implant surgery: a 2-year follow-up study of 40 implants. Oral Surg Oral Med Oral Pathol Oral Radiol. Epub July 19, 2012.

46. Bouri A, Bissada N, Al-Zahrani MS, Faddoul F, Nouneh I. Width of keratinized gingiva and the health status of the supporting tissues around dental implants. Int J Oral Maxillofac Implants. 2008;23(2): $323-326$.
Clinical, Cosmetic and Investigational Dentistry

\section{Publish your work in this journal}

Clinical, Cosmetic and Investigational Dentistry is an international, peer-reviewed, open access, online journal focusing on the latest clinical and experimental research in dentistry with specific emphasis on cosmetic interventions. Innovative developments in dental materials, techniques and devices that improve outcomes and patient satisfac-

\section{Dovepress}

tion and preference will be highlighted. The manuscript management system is completely online and includes a very quick and fair peerreview system, which is all easy to use. Visit http://www.dovepress. com/testimonials.php to read real quotes from published authors. 